\title{
Does universal health insurance coverage reduce unmet healthcare needs in China? Evidence from the National Health Service Survey
}

Shenping Zhou' ${ }^{1}$, Tianyu Huang ${ }^{1}$, Anqi Li ${ }^{1}$ and Zhonghua Wang ${ }^{1,2,3^{*}}$ (D)

\begin{abstract}
Background: China has nearly achieved universal health insurance coverage, but considerable unmet healthcare needs still exist. Although this topic has attracted great attention, there have been few studies examining the relationship between universal health insurance coverage and unmet healthcare needs. This study aimed to clarify the impact of universal health insurance coverage and other associated factors on Chinese residents' unmet healthcare needs.

Methods: Data was derived from the fourth, fifth, and sixth National Health Service Survey of Jiangsu Province, which were conducted in 2008, 2013, and 2018, respectively. Descriptive statistics were used to analyze the prevalence of unmet healthcare needs. Binary multivariate logistic regression was used to estimate the association between unmet healthcare needs and universal health insurance coverage, along with other socioeconomic factors.

Results: $8.99 \%, 1.37 \%, 53.37 \%$, and $13.16 \%$ of the respondents in Jiangsu Province reported non-use of outpatient services, inpatient services, physical examinations, and early discharge from hospital, respectively. The trend in the prevalence of unmet healthcare needs showed a decline from 2008 to 2018. Health insurance had a significant reducing effect on non-use of outpatient services, inpatient services, or early discharge from hospital. People having health insurance in 2013 and 2018 were significantly less likely to report unmet healthcare needs compared to those in 2008. The effect of health insurance and its universal coverage on reducing unmet healthcare needs was greater in rural than in urban areas. Other socioeconomic factors, such as age, marital status, educational level, income level, or health status, also significantly affected unmet healthcare needs.

Conclusions: Universal health insurance coverage has significantly reduced Chinese residents' unmet healthcare needs. Policy efforts should pay more attention to the benefits of health insurances in rural areas and optimize urban-rural health resources to promote effective utilization of healthcare.
\end{abstract}

Keywords: Universal health insurance coverage, Unmet healthcare needs, Non-use of healthcare services, Inequality

\footnotetext{
* Correspondence: wzh04@njmu.edu.cn

'School of Health Policy \& Management, Nanjing Medical University, 101Longmian Avenue, Jiangning District, Nanjing 211166, P.R. China

${ }^{2}$ Creative Health Policy Research Group, Nanjing Medical University, Nanjing 211166, China

Full list of author information is available at the end of the article
}

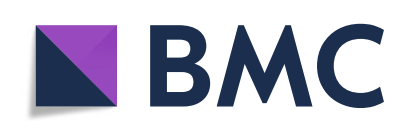

(- The Author(s). 2021 Open Access This article is licensed under a Creative Commons Attribution 4.0 International License, which permits use, sharing, adaptation, distribution and reproduction in any medium or format, as long as you give appropriate credit to the original author(s) and the source, provide a link to the Creative Commons licence, and indicate if changes were made. The images or other third party material in this article are included in the article's Creative Commons licence, unless indicated otherwise in a credit line to the material. If material is not included in the article's Creative Commons licence and your intended use is not permitted by statutory regulation or exceeds the permitted use, you will need to obtain permission directly from the copyright holder. To view a copy of this licence, visit http://creativecommons.org/licenses/by/4.0/. The Creative Commons Public Domain Dedication waiver (http://creativecommons.org/publicdomain/zero/1.0/) applies to the data made available in this article, unless otherwise stated in a credit line to the data. 


\section{Introduction}

The World Health Organization defines universal health coverage (UHC) as the ability for all people to access equal health services that are effective and do not expose the user to financial hardship [1], and this is a major sustainable development goal all over the world. These health services include health promotion, prevention, treatment, rehabilitation, and palliative care [2]. Social health insurance can effectively reduce the medical burden and promote the utilization and accessibility of health services [3-5]. And the improvement of its coverage can effectively reduce the inequality of health service utilization caused by financial hardship, improve the utilization and accessibility of health services and reduce the degree of healthcare underutilization, so as to promote the realization of UHC [6, 7].With the implementation of the New Medical Reform Plan in 2009, China has established a social health insurance system framework consisting of Urban Employees Medical Insurance, Urban Residents' Medical Insurance, and the New Rural Cooperative Medical Scheme, and these cover the employed urban population, unemployed urban residents, and rural residents, respectively. Outpatient services, inpatient services, critical illness mutual assistance, etc. are all included in the social health insurance. Health insurance coverage rate dramatically rose from $22 \%$ in 2003 to nearly $97 \%$ in 2019 [8]. China now has almost complete universal health insurance coverage, but there is still a dramatic disparity between universal health insurance coverage and universal health coverage [9].

Among the three systems, UEMI was first formally established in 1998, all the employed in urban areas should participate UEMI compulsorily and the health insurance premiums of UEMI are shared by both employers and employees. Followed by the release of "Decision of the CPC Central Committee and the State Council on Further Strengthening Rural Health Work" [10], NRCM was established in 2003. It is a health insurance system jointly funded by individuals, collectives and the government. Every local government has an escalating mandatory standard for improving coverage each year. Furthermore, in practice, if one family member was not insured, the whole family would be refused to participate in the insurance, therefore, NRCM is actually mandatory. URMI was established in 2007 and the health insurance premiums is mainly paid by families (individuals) and government subsidies. Although the original design of URMI is voluntary, it also has the binding problem--insured in family-unit, and the proportion of people directly participating in the insurance in individuals is very low, so it is partially mandatory indeed.
Equitable access to healthcare according to need, regardless of demographic, ability to pay, or social background is the main connotation of UHC [11]. Although a series of reforms to health insurance have been implemented since the New Medical Reform Plan in 2009, healthcare access in China remains highly unequal across different sub-populations and different areas [12].As a commonly used indicator of access to healthcare, unmet need is defined as the subjective perception of not receiving appropriate medical help when it is required [13-15]. Compared with healthcare utilization, the degree of healthcare underutilization can accurately reflect healthcare accessibility because healthcare utilization only reflect the actual use of health services by demanders(effective demand), which can not truly and concretely represent the whole healthcare demand [16-18]. Unmet healthcare needs are mainly a result of limited availability or unavailability of healthcare services, such as outpatient visits, hospitalization, or physical examinations, when they are needed [19]. People often choose not to use health services for reasons such as their cost, the travel distance required, their quality, the equipment available in medical institutions, or a lack of knowledge about health. This is one of the most important healthcare access issues that needs to be addressed, because unmet medical needs can not only result in a population having a poorer health status but can also lead to increasing health inequalities, thus affecting UHC [20].

Many studies have explored non-use of healthcare services and its associated factors. Several studies indicate an association between higher rates of non-use of healthcare services and female sex, younger age, rural living, lack of health insurance, lack of financial support, low levels of education, and poor health [12, 14, 21-26]. For example, $\mathrm{Li}$ et al. reported that social health insurance could significantly reduce foregone care in outpatient and inpatient situations [27]. Lucevic et al. confirmed that the most vulnerable groups at risk of unmet healthcare needs were women, those with only a primary or secondary education, people with poor health status, those living outside the capital, and those from the lowest income quintiles [15]. Sibley and Glazier found that unmet need was more common among women, younger people, those with higher educational attainment, and those with lower household income [10]. Ronksley et al. found that chronic conditions and distress were significantly associated with unmet healthcare needs [22]. However, most studies focusing on underutilization of healthcare have been limited to specific sub-populations or specific areas [28] or have focused on only one type of non-use of health services [26, 29-34]. With respect to those studies that have examined health insurance, most have focused on a certain 
kind of health insurance or were limited to crosssectional data [35-39].

Although researchers and policymakers are highly interested in unmet healthcare needs, studies on the association between universal health insurance coverage and unmet healthcare needs are scarce in China. With the rapid improvement of social health insurance coverage after the New Medical Reform Plan 2009, it is imperative to explore the impact of the process of universal coverage of health insurance on health services underutilization. In this paper, we used data from the National Health Service Surveys in Jiangsu Province in China (2008-2018) to explore whether full health insurance coverage actually reduces unmet healthcare needs. The survey results represent pooled cross-sectional data that span the period of universal implementation of the basic health insurance system in China. We calculated the prevalence of healthcare underutilization, analyzed the main causes of unmet healthcare needs, and compared the prevalence of healthcare underutilization between urban and rural areas. Furthermore, we estimated the association between universal health insurance coverage, other socioeconomic factors, and unmet healthcare needs. The results of this study will provide scientific evidence for improving the social health insurance policy and improving the accessibility of health services, so as to achieve universal health coverage.

\section{Methods}

\section{Data sources}

The data came from the fourth, fifth, and sixth National Health Service Survey (NHSS) of Jiangsu Province in 2008, 2013, and 2018, respectively. The NHSS is a five-yearly survey administered by the Center for Health Statistics and Information of the National Health Commission. The survey adopted the method of multi-stage stratified random sampling, and a total of 156 counties (cities and districts) in 31 provinces were selected. Five sample towns (streets) were randomly selected for each sample county (cities or districts), two sample villages (neighborhood committees) were randomly selected for each sample town (street), and 60 households were randomly selected for each sample village (neighborhood committee), examining a total of 93,600 households (a population of nearly 300,000 people). Jiangsu Province is a densely populated area located in the east of mainland of China and has a population of 80.293 million. Nineteen counties were sampled in the NHSS of Jiangsu Province, and the numbers of respondents were $7021,10,466$, and 11,550 in 2008, 2013, and 2018, respectively. Excluding missing data, the total sample in the study contained 25,048 respondents aged over 13. As mentioned above, this sample, spanning 10 years, covers the period of the introduction of full health insurance coverage.

The data from the NHSS includes detailed information about the individuals in households, and the questionnaire included questions about the demographic and socioeconomic characteristics of urban and rural residents, including their sex, marital status, educational level, family size, employment status, income level, self-reported health status, and existing illnesses. The questionnaire also examined urban and rural residents' healthcare-service needs, utilization, and underutilization, as well as health insurance. Furthermore, it included questions about reasons for not seeking outpatient care (1. Illness is not serious; 2 . Financial difficulties; 3 . The procedure of seeing a doctor is too complex; 4. Having no time; 5. Transportation problems; 6 . No effective treatment; 7. Other), reasons for not seeking inpatient care (1. It is unnecessary; 2. No effective treatment; 3 . Financial difficulties; 4. Poor service of hospital; 5. Having no time; 6 . There is no bed available; 7 . Other), and reasons for early discharge from hospital (1. Cannot recover from illness; 2 . Think oneself recovered; 3 . Financial difficulties; 4. It costs too much; 5. Poor hospital facilities; 6. Poor medical technology at the hospital; 7. Other). The variables included in the multivariate model are presented in Table 1.

\section{Statistical analysis \\ Descriptive analysis}

Descriptive statistics were used to analyze the sample characteristics, including the prevalence of main reasons for and trends in reported unmet healthcare needs in rural and urban households.

\section{Regression analysis}

Binary multivariate logistic regression was used to estimate the association between unmet healthcare needs and universal health insurance coverage, along with other factors. Our analysis included a regression of unmet health services and a regression of the main causes of unmet health services. For the first regression, the dependent variable, unmet healthcare need, was defined by "non-use of health services", which was dichotomized into $0=$ "no reported non-use of health services" and 1 $=$ "reported non-use of health services". For the second regression, the dependent variable "main reason for unmet healthcare need" was defined as follows: "main reason" $=1$ and "other reasons" $=0$. Comprehensive analyses were conducted, and all data collation and statistical analyses were performed using SPSS 22.0 and Stata 24.0. 
Table 1 Descriptions of dependent and independent variables

\begin{tabular}{|c|c|c|}
\hline & Categories & Indicators/survey questions \\
\hline \multicolumn{3}{|l|}{ Dependent variables } \\
\hline $\begin{array}{l}\text { Non-use of outpatient } \\
\text { services }\end{array}$ & $\begin{array}{l}=1, \text { Reported non-use of out- } \\
\text { patient services } \\
=0, \text { No reported non-use of } \\
\text { outpatient services }\end{array}$ & $\begin{array}{l}\text { Questions: Have you been ill in the last two weeks? What was the main reason for not } \\
\text { seeking outpatient treatment? }\end{array}$ \\
\hline $\begin{array}{l}\text { Non-use of inpatient } \\
\text { services }\end{array}$ & $\begin{array}{l}=1, \text { Reported non-use of in- } \\
\text { patient services } \\
=0 \text {, No reported non-use of } \\
\text { inpatient services }\end{array}$ & $\begin{array}{l}\text { Question: In the past year, did a doctor suggest that you needed inpatient care but you } \\
\text { were not hospitalized? What was the main reason for not seeking inpatient treatment? }\end{array}$ \\
\hline $\begin{array}{l}\text { Non-use of physical } \\
\text { examinations }\end{array}$ & $\begin{array}{l}=1 \text {, Did not undergo physical } \\
\text { examination } \\
=0 \text {, Underwent physical } \\
\text { examination }\end{array}$ & Question: Have you had a physical examination in the past 12 months? \\
\hline $\begin{array}{l}\text { Early discharge from the } \\
\text { hospital }\end{array}$ & $\begin{array}{l}=1, \text { Reported early discharge } \\
\text { from the hospital } \\
=0, \text { No reported early } \\
\text { discharge from the hospital }\end{array}$ & $\begin{array}{l}\text { Question: In the year before the survey, were you ever discharged early from hospital? } \\
\text { What was the main } \\
\text { reason for your self-discharge? }\end{array}$ \\
\hline \multicolumn{3}{|l|}{ Independent variables } \\
\hline \multicolumn{3}{|l|}{ Predisposing factors } \\
\hline Sex & $=1$, Male $=2$, Female & Question: What is your sex? \\
\hline Age (years) & $\begin{array}{l}=1 \text {, if } \leq 30 ;=2,30-45 ;=3,45- \\
60 ;=4 \text {, if } \geq 60\end{array}$ & Question: Year of birth. \\
\hline Marital status & $=1$, not married; $=2$, married & $\begin{array}{l}\text { Question: What is your marital status? (Widowhood and divorce both belong to "not } \\
\text { married".) }\end{array}$ \\
\hline $\begin{array}{l}\text { Employment/ } \\
\text { retirement status }\end{array}$ & $\begin{array}{l}=1, \text { employed; }=2, \text { not } \\
\text { employed; }=3 \text {, retired }\end{array}$ & Question: What is your employment status? \\
\hline Education level & $\begin{array}{l}=1 \text {, less than lower } \\
\text { secondary; } \\
=2 \text {, upper secondary \& } \\
\text { vocational training; } \\
=3 \text {, tertiary }\end{array}$ & Question: What is your education level? \\
\hline Family size & $\begin{array}{l}=1 \text {, if } \leq 2 \text { persons in } \\
\text { household; } \\
=2, \text { if } \geq 3 \text { persons in } \\
\text { household }\end{array}$ & Number of household members \\
\hline \multicolumn{3}{|l|}{ Enabling factors } \\
\hline $\begin{array}{l}\text { Social health } \\
\text { insurance }\end{array}$ & $\begin{array}{l}=1 \text {, have insurance; } \\
=0 \text {, have no insurance }\end{array}$ & Question: Do you have any social health insurance? \\
\hline Income level & $\begin{array}{l}=1, \leq ¥ 13,334 ; \\
=2, ¥ 13,334-24,915 ; \\
=3, ¥ 24,915-39,967 ; \\
=4, \geq ¥ 39,967\end{array}$ & $\begin{array}{l}\text { Yearly household income divided by the number of household members; first } \\
\text { household member with a weight of } 1 \text {, all following household members with a weight } \\
\text { of } 0.5 \text {. }\end{array}$ \\
\hline Area of residence & $\begin{array}{l}=1 \text {, urban; } \\
=2 \text {, rural }\end{array}$ & Question: What is your registered type? \\
\hline Financial subsidies & $\begin{array}{l}=1 \text {, financial subsidies from } \\
\text { government } \\
=2, \text { no financial subsidies } \\
\text { from government }\end{array}$ & $\begin{array}{l}\text { Whether the respondent was a Medicaid recipient or in a poor household or low- } \\
\text { income household }\end{array}$ \\
\hline \multicolumn{3}{|l|}{ Need variables } \\
\hline $\begin{array}{l}\text { Self-reported health } \\
\text { status(Value on VAS) }\end{array}$ & $\begin{array}{l}=1 \text {, excellent }(80-100) ; \\
=2, \text { good }(70-80) ; \\
=3 \text {, fair }(50-70) \\
=4, \text { poor }(\leq 49)\end{array}$ & Question: Which score best represents your health today? \\
\hline Chronic diseases & $\begin{array}{l}=0, \text { no chronic; } \\
=1 \text {, one chronic; } \\
=2 \text {, multiple chronic diseases }\end{array}$ & $\begin{array}{l}\text { Questions: Do you have confirmed hypertension? } \\
\text { Do you have confirmed diabetes? } \\
\text { Do you have other chronic diseases diagnosed? }\end{array}$ \\
\hline Depression & $=1$, depressed; & Question: What is the extent of your anxiety or depression? \\
\hline
\end{tabular}


Table 1 Descriptions of dependent and independent variables (Continued)

\begin{tabular}{|c|c|c|}
\hline & Categories & Indicators/survey questions \\
\hline & $=0$, not depressed & \\
\hline Drinking & $\begin{array}{l}=1, \text { yes; } \\
=2, \text { no }\end{array}$ & Whether the respondent ever drank alcoholic beverages or is presently a drinker \\
\hline Smoking & $\begin{array}{l}=1, \text { yes; } \\
=2, \text { no }\end{array}$ & Whether the respondent reports ever having smoked or is presently a smoker \\
\hline
\end{tabular}

\section{Variable selection}

\section{Dependent variables}

The dependent variables included four kinds of unmet healthcare needs: non-use of outpatient services (a person perceived a need for outpatient care in the past 2 weeks but did not seek outpatient treatment), non-use of inpatient services (a person a perceived a need for inpatient care during the past year but was not hospitalized), non-use of physical examinations (whether or not a person underwent physical examinations in the past year), and early discharge from hospital (whether or not a person was discharged early from hospital in the past year). Furthermore, respondents were asked to specify why they did not seek healthcare treatment. It should be noted that the reasons for physical examinations were not included in the study.

\section{Independent variables}

Based on the Andersen healthcare utilization model, which has guided systematic investigations into the factors associated with healthcare utilization, we categorized the independent variables into three types: predisposing variables, enabling variables, and need variables [40]. Predisposing factors included demographic characteristics and social structure factors, such as sex, age, marital status, employment status, education level, and family size. Enabling factors included organizational and financial variables that facilitate healthcare utilization [15], consisting of social health insurance, income level, area of residence, and whether financial subsidies are received (in China, the lowest-income households were identified by local governments and subsidized by the local bureau of civil affairs). Taking inflation into account, all income was converted to the price level in 2018 using a price index from China Statistical Yearbook. Need factors refer to both subjective need (self-perceived) and objective need (diagnosed or evaluated by healthcare professionals) for healthcare utilization. The former included self-reported health status, and the latter included smoking, drinking, depression, and chronic diseases. Furthermore, to estimate the effect of the whole process of universal health insurance coverage on unmet healthcare needs, we introduced year dummies and cross-variables of insurance interacting with these year dummies. Detailed descriptions of the samples are included in Table 2.

\section{Results \\ Sample characteristics}

As shown in Table 2, among all respondents in Jiangsu province, 43.81\% (10973) were urban residents and $56.19 \%$ (14075) were rural residents, and 23.95, 36.82, and $39.23 \%$ were from the NHSS in 2008, 2013, and 2018, respectively. More than two-thirds of people (74.29\%) had a larger family size (>2). People with lower education levels (less than secondary) in rural areas accounted for $80.26 \%$, which was higher than in urban areas $(53.71 \%)$. In urban areas, almost half of residents were retired or unemployed, compared with approximately $21 \%$ in rural areas. There were more people in the highest income group $(>39,967)$ in urban areas (39.78\%) than in rural areas (13.23\%). The insurance coverage rate exceeded $95 \%$ in both urban and rural areas. Of which, $11.87 \%$ of the respondents participated in URMI, and $28.55 \%$ in NRCM. The proportion of people who were depressed was $5.17 \%$. The proportions of people whose self-reported health status was excellent were 75.19 and $76.53 \%$ in urban and rural areas, respectively. The proportion of people with one or multiple chronic diseases was higher in urban areas (26.60 and $9.84 \%)$ than in rural areas (21.17 and 5.49\%).

\section{Prevalence of, reasons for, and trends in unmet healthcare needs}

Table 3 details the prevalence of and the reasons for unmet healthcare needs in Jiangsu province. The trends in unmet healthcare needs from 2008 to 2018 are also shown in Figs. 1, 2, 3. Overall, the prevalence of non-use of outpatient services was $8.99 \%$, which was higher in urban areas (11.63\%) than in rural areas (6.93\%). The overall main reason for not seeking outpatient services was "Illness is not serious" (11.68\%), and this was also true in urban areas (7.94\%). However, in rural areas, the main reason was "No effective treatment" (44.84\%). The total prevalence of non-use of inpatient services and physical examinations were 1.37 and 53.37\%, respectively. The corresponding figures were higher among people in rural areas than those in urban areas. The overall primary reason for not seeking inpatient services was "Financial difficulties" (35.73\%), and this was also the main reason in rural areas (41.41\%); however, in urban areas, "It is 
Table 2 Sample characteristics divided by living areas (urban \& rural)

\begin{tabular}{|c|c|c|c|c|}
\hline & $\begin{array}{l}\text { Total } \\
n=25,048\end{array}$ & $\begin{array}{l}\text { Urban } \\
n=10,973(43.81 \%)\end{array}$ & $\begin{array}{l}\text { Rural } \\
n=14,075(56.19 \%)\end{array}$ & $\begin{array}{l}p \\
\text { value }\end{array}$ \\
\hline Year & & & & 0.000 \\
\hline 2008 & $23.95 \%$ & $12.73 \%$ & $32.69 \%$ & \\
\hline 2013 & $36.82 \%$ & $42.61 \%$ & $32.31 \%$ & \\
\hline 2018 & $39.23 \%$ & $44.66 \%$ & $35.00 \%$ & \\
\hline \multicolumn{5}{|l|}{ Predisposing factors } \\
\hline Sex & & & & 0.055 \\
\hline Male & $48.85 \%$ & $48.16 \%$ & $49.39 \%$ & \\
\hline Female & $51.15 \%$ & $51.84 \%$ & $50.61 \%$ & \\
\hline Age (years) & & & & 0.000 \\
\hline$\leq 30$ & $17.45 \%$ & $16.99 \%$ & $17.80 \%$ & \\
\hline $30-45$ & $21.10 \%$ & $20.39 \%$ & $21.66 \%$ & \\
\hline $45-60$ & $30.32 \%$ & $26.34 \%$ & $33.42 \%$ & \\
\hline$>60$ & $31.13 \%$ & $36.28 \%$ & $27.11 \%$ & \\
\hline Family size & & & & 0.000 \\
\hline$\leq 2$ & $25.71 \%$ & $30.75 \%$ & $21.79 \%$ & \\
\hline$>2$ & $74.29 \%$ & $69.25 \%$ & $78.21 \%$ & \\
\hline Marital status & & & & 0.006 \\
\hline Married & $80.70 \%$ & $79.92 \%$ & $81.31 \%$ & \\
\hline Not married & $19.30 \%$ & $20.08 \%$ & $18.69 \%$ & \\
\hline Education level & & & & 0.000 \\
\hline Less than lower secondary & $68.63 \%$ & $53.71 \%$ & $80.26 \%$ & \\
\hline Upper secondary \& vocational training & $18.36 \%$ & $23.48 \%$ & $14.37 \%$ & \\
\hline Tertiary & $13.01 \%$ & $22.81 \%$ & $5.37 \%$ & \\
\hline Employment status & & & & 0.000 \\
\hline Employed & $64.94 \%$ & $48.55 \%$ & $77.71 \%$ & \\
\hline Not employed & $19.53 \%$ & $19.02 \%$ & $19.94 \%$ & \\
\hline Retired & $15.53 \%$ & $32.43 \%$ & $2.35 \%$ & \\
\hline \multicolumn{5}{|l|}{ Enabling factors } \\
\hline Income level & & & & 0.000 \\
\hline$\leq ¥ 13,334$ & $25.44 \%$ & $8.38 \%$ & $38.74 \%$ & \\
\hline$¥ 13,334-24,915$ & $24.60 \%$ & $19.45 \%$ & $28.61 \%$ & \\
\hline$¥ 24,915-39,967$ & $25.10 \%$ & $32.39 \%$ & $19.42 \%$ & \\
\hline$>¥ 39,967$ & $24.86 \%$ & $39.78 \%$ & $13.23 \%$ & \\
\hline Financial subsidies & & & & 0.000 \\
\hline Yes & $3.78 \%$ & $2.83 \%$ & $4.53 \%$ & \\
\hline No & $96.22 \%$ & $97.17 \%$ & $95.47 \%$ & \\
\hline Social health insurance & & & & 0.000 \\
\hline Yes & $96.47 \%$ & $96.14 \%$ & $96.74 \%$ & \\
\hline No & $3.53 \%$ & $3.86 \%$ & $3.26 \%$ & \\
\hline \multicolumn{5}{|l|}{ Need factors } \\
\hline Depression & & & & 0.000 \\
\hline Not depressed & $94.83 \%$ & $96.26 \%$ & $93.71 \%$ & \\
\hline Depressed & $5.17 \%$ & $3.74 \%$ & $6.29 \%$ & \\
\hline
\end{tabular}


Table 2 Sample characteristics divided by living areas (urban \& rural) (Continued)

\begin{tabular}{|c|c|c|c|c|}
\hline & $\begin{array}{l}\text { Total } \\
n=25,048\end{array}$ & $\begin{array}{l}\text { Urban } \\
n=10,973(43.81 \%)\end{array}$ & $\begin{array}{l}\text { Rural } \\
n=14,075 \text { (56.19\%) }\end{array}$ & $\begin{array}{l}p \\
\text { value }\end{array}$ \\
\hline Self-reported health status (value on VAS) & & & & 0.000 \\
\hline Excellent (80-100) & $75.95 \%$ & $75.19 \%$ & $76.53 \%$ & \\
\hline Good (70-80) & $12.84 \%$ & $14.01 \%$ & $11.93 \%$ & \\
\hline Fair (50-70) & $9.78 \%$ & $9.63 \%$ & $9.90 \%$ & \\
\hline Poor $(<50)$ & $1.43 \%$ & $1.17 \%$ & $1.64 \%$ & \\
\hline Smoking & & & & 0.056 \\
\hline Yes & $26.05 \%$ & $25.45 \%$ & $26.52 \%$ & \\
\hline No & $73.95 \%$ & $74.55 \%$ & $73.48 \%$ & \\
\hline Drinking & & & & 0.024 \\
\hline Yes & $22.67 \%$ & $21.99 \%$ & $23.20 \%$ & \\
\hline No & $77.33 \%$ & $78.01 \%$ & $76.80 \%$ & \\
\hline Chronic diseases & & & & 0.000 \\
\hline 0 & $69.06 \%$ & $63.56 \%$ & $73.34 \%$ & \\
\hline One & $23.55 \%$ & $26.60 \%$ & $21.17 \%$ & \\
\hline Multiple & $7.39 \%$ & $9.84 \%$ & $5.49 \%$ & \\
\hline
\end{tabular}

unnecessary" was the main reason (39.17\%). In addition, $13.16 \%$ of respondents left the hospital before recovery. As a whole, the main reason for this was "Think oneself recovered" (27.92\%), and this was also true in urban areas (39.76\%). However, in rural areas the leading reason for early discharge from hospital was "Other reasons" (25.27\%), followed by "Financial difficulties" (24.73\%).

With regard to the trend in unmet healthcare needs, on the whole, the underutilization rates in urban and rural areas were similar. The overall rates of non-use of outpatient services (2008:3.00\%; 2018:0.36\%), non-use of physical examinations (2008:71.87\%; 2018:47.51\%), and early discharge from hospital (2008:22.01\%; 2018: 7.84\%) all showed decreasing trends. However, in 2013, the rate of non-use of outpatient services (2013:28.35\%) showed a dramatic rise, followed by a significant decline from 2013 to 2018. For non-use of inpatient services, the rate remained relatively lower and was flat from 2008 to 2018(2008:1.20\%; 2013:1.05\%; 2018:1.77\%). Furthermore, the range of fluctuation in the rate of non-use of outpatient services was greater in in rural areas(2008: $3.26 \%$; 2018:0.51\%) than urban areas(2008:2.15\%; 2018 : $0.2 \%)$. The rate of non-use of physical examinations demonstrated a greater decline in rural areas(2008: $78.18 \%$; 2013:51.13\%\%) than in urban areas(2008: $51.11 \%$; 2013:44.14\%) from 2008 to 2013. In addition, the decline in the rate of early discharge from hospital was more significant in rural areas(2008:26.59\%; 2018: 9.18\%) than in urban areas(2008:12.79\%; 2018:6.06\%) from 2008 to 2018 .

\section{Multivariate regression results Logistic regression of unmet healthcare needs}

The data shown in Table 4 indicate that people aged over 60 demonstrated a significantly higher likelihood of reporting non-use of outpatient services $(\mathrm{OR}=2.045)$, non-use of inpatient services $(\mathrm{OR}=1.672)$, and early discharge from hospital $(\mathrm{OR}=2.187)$. However, the correlation was opposite in the non-use of physical examinations $(\mathrm{OR}=0.337)$. Those who had received tertiary education were significantly less likely to report underutilization of all kinds of healthcare services. Unemployed or retired people demonstrated a higher probability of non-use of inpatient services (retired: $\mathrm{OR}=1.373$ ) and physical examinations (unemployed: $\mathrm{OR}=1.507$ ). Those living in larger families (households $>2$ people) were significantly less likely to report outpatient $(\mathrm{OR}=0.954)$ and inpatient underutilization $(\mathrm{OR}=0.905)$.

Regarding enabling factors, we found that having health insurance was correlated with a significantly lower probability of non-use of outpatient $(\mathrm{OR}=0.492)$ and inpatient $(\mathrm{OR}=0.586)$ services and early discharge from hospital $(\mathrm{OR}=0.943)$. The highest income group was significantly less likely to report healthcare underutilization. In addition, receiving financial subsidies was correlated with a significantly lower likelihood of inpatient underutilization ( $\mathrm{OR}=0.581)$ and early discharge from hospital $(\mathrm{OR}=0.904)$. Rural residents were significantly more likely to report non-use of health services than urban residents. Among need factors, the likelihood of underutilization of outpatient $(\mathrm{OR}=1.309)$ and 
Table 3 Prevalence and reasons of unmet healthcare needs

\begin{tabular}{|c|c|c|c|c|}
\hline & total & urban & rural & P值 \\
\hline Non-use of outpatient services & $8.99 \%(2252)$ & $11.63 \%(1276)$ & $6.93 \%(976)$ & 0.000 \\
\hline 2008 & $3.00 \%$ & $2.15 \%$ & $3.26 \%$ & \\
\hline 2013 & $28.35 \%$ & $26.43 \%$ & $17.62 \%$ & \\
\hline 2018 & $0.36 \%$ & $0.20 \%$ & $0.51 \%$ & \\
\hline Reasons for not seeking outpatient services & & & & 0.000 \\
\hline Illness is not serious & $11.68 \%$ & $7.94 \%$ & $16.56 \%$ & \\
\hline Financial difficulties & $2.76 \%$ & $0.79 \%$ & $5.35 \%$ & \\
\hline The procedure of seeing a doctor is complex & $0.40 \%$ & $0.39 \%$ & $0.41 \%$ & \\
\hline Having no time & $0.76 \%$ & $0.16 \%$ & $1.34 \%$ & \\
\hline Transportation problems & $0.09 \%$ & $0.08 \%$ & $0.10 \%$ & \\
\hline No effective treatment & $2.41 \%$ & $0.55 \%$ & $44.84 \%$ & \\
\hline Other & $82.00 \%$ & $90.09 \%$ & $71.40 \%$ & \\
\hline Non-use of inpatient services & $1.37 \%(343)$ & $1.10 \%(121)$ & $1.58 \%(222)$ & 0.001 \\
\hline 2008 & $1.20 \%$ & $1.15 \%$ & $1.22 \%$ & \\
\hline 2013 & $1.05 \%$ & $0.88 \%$ & $1.23 \%$ & \\
\hline 2018 & $1.77 \%$ & $1.31 \%$ & $2.23 \%$ & \\
\hline Reasons for not seeking inpatient services & & & & 0.000 \\
\hline It is unnecessary & $27.38 \%$ & $39.17 \%$ & $21.15 \%$ & \\
\hline No effective treatment & $4.32 \%$ & $5.00 \%$ & $3.96 \%$ & \\
\hline Financial difficulties & $35.73 \%$ & $25.00 \%$ & $41.41 \%$ & \\
\hline Poor service of hospital & $0.86 \%$ & $1.67 \%$ & $0.44 \%$ & \\
\hline Having no time & $15.56 \%$ & $5.83 \%$ & $20.70 \%$ & \\
\hline There is no bed available & $2.59 \%$ & $5.83 \%$ & $0.88 \%$ & \\
\hline Other & $13.54 \%$ & $17.50 \%$ & $11.45 \%$ & \\
\hline Non-use of physical examination & $53.37 \%(13,369)$ & $43.69 \%(4794)$ & $60.92 \%(8575)$ & 0.000 \\
\hline 2008 & $71.87 \%$ & $51.11 \%$ & $78.18 \%$ & \\
\hline 2013 & $47.59 \%$ & $44.14 \%$ & $51.13 \%$ & \\
\hline 2018 & $47.51 \%$ & $44.14 \%$ & $53.85 \%$ & \\
\hline Early discharge from hospital & $13.16 \%(268)$ & $8.43 \%(85)$ & $17.80 \%(183)$ & 0.000 \\
\hline 2008 & $22.01 \%$ & $12.79 \%$ & $26.59 \%$ & \\
\hline 2013 & $17.65 \%$ & $10.88 \%$ & $24.86 \%$ & \\
\hline 2018 & $7.84 \%$ & $6.06 \%$ & $9.78 \%$ & \\
\hline Reasons for Early discharge from hospital & & & & 0.000 \\
\hline Cannot recover from illness & $10.19 \%$ & $13.25 \%$ & $8.79 \%$ & \\
\hline Think oneself recovered & $27.92 \%$ & $39.76 \%$ & $22.53 \%$ & \\
\hline Financial difficulties & $20.00 \%$ & $9.64 \%$ & $24.73 \%$ & \\
\hline Cost too much & $12.45 \%$ & $9.64 \%$ & $13.74 \%$ & \\
\hline Poor hospital facilities & $1.51 \%$ & $0.00 \%$ & $2.20 \%$ & \\
\hline Poor medical technology at the hospital & $3.02 \%$ & $3.61 \%$ & $2.75 \%$ & \\
\hline Other & $24.91 \%$ & $24.10 \%$ & $25.27 \%$ & \\
\hline
\end{tabular}

inpatient services $(O R=2.509)$ was significantly higher among people with a poor health status. The depressed demonstrated a higher likelihood of healthcare underutilization. People with one or multiple chronic diseases had a significantly higher probability of non-use of outpatient services $(\mathrm{OR}=1.985,3.063)$ and inpatient 


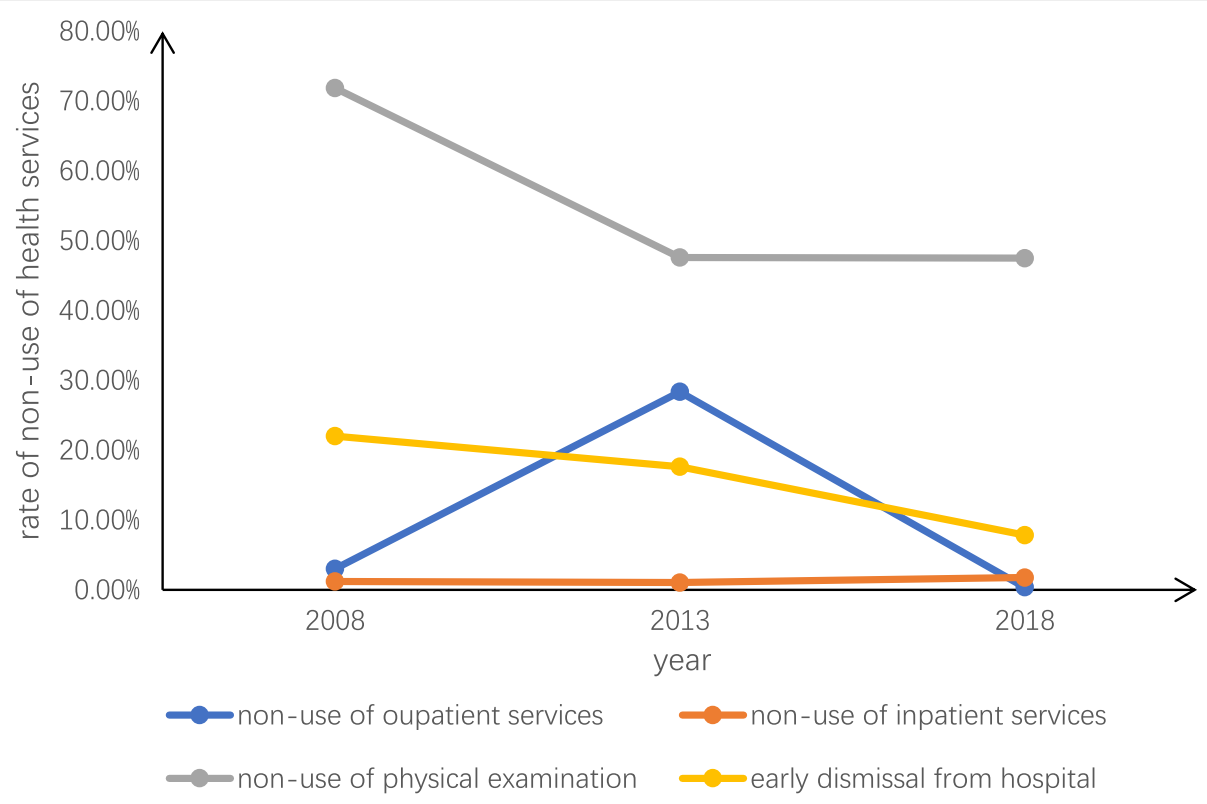

Fig. 1 Trends in overall unmet healthcare needs

services $(\mathrm{OR}=1.973,2.522)$, but showed a lower likelihood of underutilization of physical examinations (OR $=0.744,0.253)$.

The probability of non-use of outpatient services and physical examinations was significantly lower both in $2013(\mathrm{OR}=0.861,0.773)$ and $2018(\mathrm{OR}=0.603,0.581)$ than in 2008, and the corresponding odds ratios declined from 2013 to 2018. In addition, the likelihoods of nonuse of inpatient services $(\mathrm{OR}=0.547)$ and early discharge from hospital (0.487) in 2018 were significantly lower than in 2008. According to the coefficient, people with health insurance both in 2013 and 2018 demonstrated a significantly lower likelihood of reporting non-use of outpatient services and early discharge from hospital, while the corresponding figures were both smaller in $2018(\mathrm{OR}=0.235,0.309)$ than in 2013 $(\mathrm{OR}=0.609,0.541)$. Additionally, individuals having health insurance in 2018 were also significantly less likely to report non-use of inpatient services $(\mathrm{OR}=0.432)$.

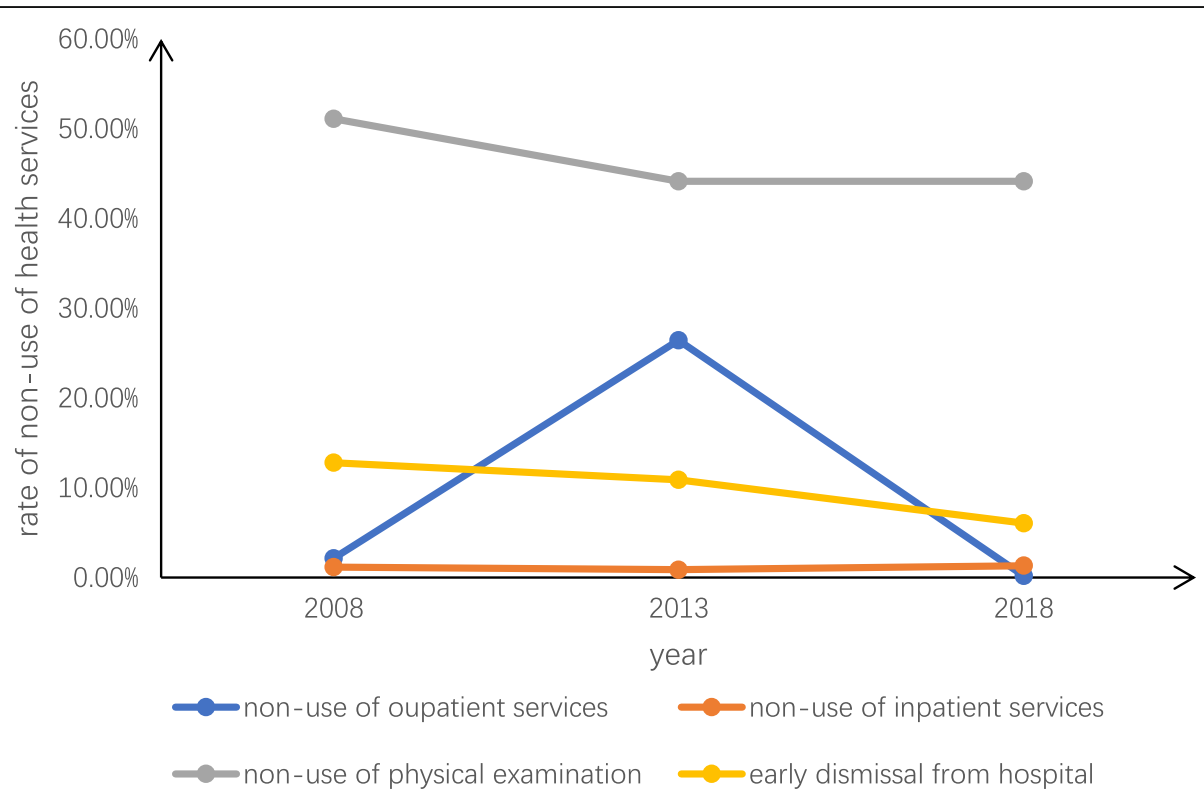

Fig. 2 Trends in urban unmet healthcare needs 


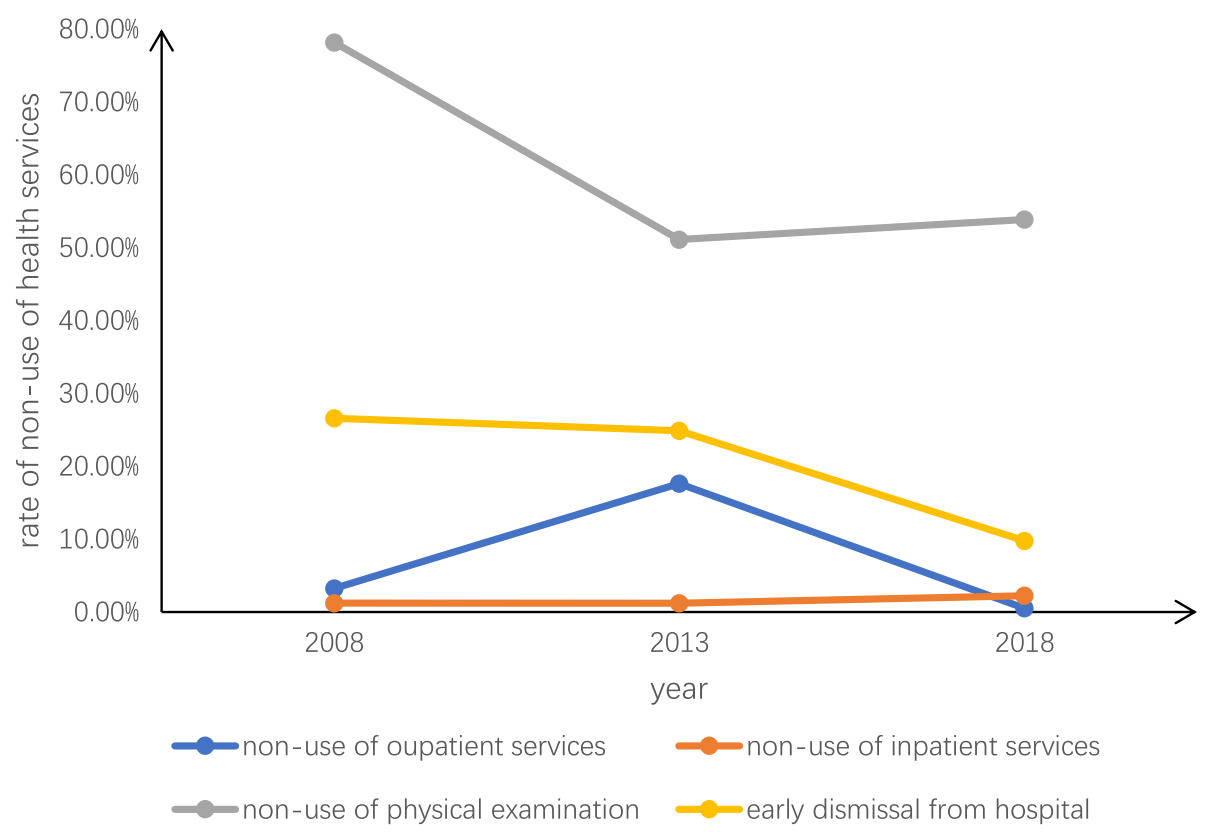

Fig. 3 Trends in rural unmet healthcare needs

Tables 5 and 6 show logistic regressions of the nonuse of health services among people living in urban and rural areas, respectively. The married demonstrated a significantly lower likelihood of non-use of outpatient services $(\mathrm{OR}=0.749)$ and physical examinations $(\mathrm{OR}=$ 0.801), and a higher likelihood of non-use of inpatient services $(O R=1.177)$ in urban areas, but there was no significant effect in rural areas. In addition, the positive effect of education level on healthcare utilization was estimated to be greater among urban residents, while the mitigating effect of a higher income level on unmet healthcare needs was greater among rural residents. The effect of health insurance on reducing the likelihood of hospitalization underutilization and early discharge was estimated to be greater in rural areas $(\mathrm{OR}=0.291,0.628)$ than in urban areas $(\mathrm{OR}=0.610,0.793)$. The likelihood of non-use of health services was significantly lower in 2018 in both rural and urban areas, but the year effect was estimated to be greater in rural areas. People having health insurance in 2018 demonstrated a significantly lower likelihood of non-use of outpatient services $(\mathrm{OR}=$ $0.689)$ and physical examinations $(\mathrm{OR}=0.947)$ in urban areas, while individuals in rural areas with health insurance both in 2013 and 2018 were significantly less likely to report non-use of outpatient (2013: OR $=0.847,2018$ : $\mathrm{OR}=0.493)$ and inpatient services $(2013: \mathrm{OR}=0.904$, 2018: $\mathrm{OR}=0.312$ ). In addition, people having health insurance in 2018 were significantly less likely to report early discharge from hospital $(\mathrm{OR}=0.271)$ in rural areas, but there was no significant effect in urban areas.

\section{Logistic regression of main reasons for unmet healthcare needs}

The results of the regression of unmet healthcare needs caused by a single main reason are shown in Table 7 . The most frequently reported reasons for not seeking outpatient care, inpatient care, and early discharge from hospital were "Illness is not serious", "Financial difficulties", and "Think oneself recovered", respectively. We found that females $(\mathrm{OR}=1.576)$ and those aged over 45 (45-60: $\mathrm{OR}=1.392 ;>60$ : $\mathrm{OR}=1.838)$ were significantly more likely to report underutilization of outpatient services for the reason "Illness is not serious". Individuals with higher education, who were retired, or had one or more chronic diseases demonstrated a significantly lower likelihood of non-use of outpatient services due to "Illness is not serious". Compared with individuals in 2008, those in 2018 were significantly less likely to report nonuse of outpatient services $(\mathrm{OR}=0.954)$ due to the cause "Illness is not serious".

Individuals aged over $60(\mathrm{OR}=1.739)$ or who were unemployed $(\mathrm{OR}=1.297)$ demonstrated a significantly higher likelihood of underutilization of inpatient services due to "Financial difficulties", while those who had received tertiary education $(\mathrm{OR}=0.874)$ and those living in larger families $(>2$ : $O R=0.903)$ exhibited a significantly lower probability of underutilization of inpatient services. Having insurance or being in a higher income group were correlated with a significantly lower likelihood of inpatient underutilization due to "Financial difficulties". In addition, people having chronic diseases were significantly more likely to report non-use of inpatient 
Table 4 Logistic regression of unmet healthcare needs among the whole population

\begin{tabular}{|c|c|c|c|c|c|c|c|c|}
\hline & \multicolumn{2}{|c|}{$\begin{array}{l}\text { Non-use of } \\
\text { outpatient services }\end{array}$} & \multicolumn{2}{|c|}{$\begin{array}{l}\text { Non-use of inpatient } \\
\text { services }\end{array}$} & \multicolumn{2}{|c|}{$\begin{array}{l}\text { Non-use of physical } \\
\text { examination }\end{array}$} & \multicolumn{2}{|c|}{$\begin{array}{l}\text { Early discharge from } \\
\text { hospital }\end{array}$} \\
\hline & OR & SD & OR & SD & OR & SD & OR & SD \\
\hline \multicolumn{9}{|l|}{ Predisposing factors } \\
\hline Sex, ref:: male & 1.283 & 0.193 & 1.210 & 0.498 & 1.125 & 0.181 & 1.156 & 0.191 \\
\hline \multicolumn{9}{|l|}{ Age (years), ref:: $\leq 30$} \\
\hline $30-45$ & $1.705^{* * *}$ & 0.258 & 1.006 & 0.745 & $0.909^{*}$ & 0.051 & 1.110 & 0.491 \\
\hline $45-60$ & $2.451^{* * *}$ & 0.153 & $1.465^{* * *}$ & 0.309 & $0.617^{*}$ & 0.139 & 1.906 & 0.874 \\
\hline$>60$ & $2.045^{* * *}$ & 0.359 & $1.672^{* *}$ & 0.295 & $0.337^{* * *}$ & 0.024 & $2.187^{*}$ & 1.188 \\
\hline Marital status, ref.: not married & 1.293 & 0.288 & 1.408 & 0.507 & 1.920 & 0.086 & 1.047 & 0.339 \\
\hline \multicolumn{9}{|l|}{ Education level, ref.: less than lower secondary } \\
\hline Upper secondary \& vocational training & 1.287 & 0.404 & 0.788 & 0.453 & $0.763^{* * *}$ & 0.048 & $0.907^{*}$ & 0.276 \\
\hline Tertiary & $0.693^{*}$ & 0.218 & $0.457^{* * *}$ & 0.121 & $0.392^{* *}$ & 0.111 & $0.521^{* *}$ & 0.104 \\
\hline \multicolumn{9}{|l|}{ Employment status, ref.: employment } \\
\hline Unemployment & 1.406 & 0.339 & 1.266 & 0.581 & $1.507^{*}$ & 0.431 & 1.751 & 1.157 \\
\hline Retired & 1.375 & 0.239 & $1.373^{* *}$ & 0.208 & 1.298 & 0.209 & 1.443 & 0.998 \\
\hline Family size, ref.: $\leq 2$ & $0.954^{*}$ & 0.168 & $0.905^{* *}$ & 0.176 & 1.030 & 0.200 & 0.774 & 0.259 \\
\hline \multicolumn{9}{|l|}{ Enabling factors } \\
\hline Social health insurance, ref.: have no insurance & $0.492^{* * *}$ & 0.094 & $0.586^{* *}$ & 0.097 & 1.251 & 0.417 & $0.943^{*}$ & 0.327 \\
\hline \multicolumn{9}{|l|}{ Income level, ref:: $\leq ¥ 13,334$} \\
\hline$¥ 13,334-24,915$ & 1.210 & 0.309 & 0.804 & 0.313 & $0.902^{* * *}$ & 0.011 & 1.094 & 0.469 \\
\hline$¥ 24,915-39,967$ & $0.902^{* *}$ & 0.183 & $0.512^{* * *}$ & 0.092 & $0.496^{* * *}$ & 0.020 & 1.336 & 0.764 \\
\hline$>¥ 39,967$ & $0.783^{*}$ & 0.093 & $0.483^{* *}$ & 0.102 & $0.410^{* * *}$ & 0.030 & $0.689^{* *}$ & 0.244 \\
\hline Financial subsidies: ref:: have financial subsidies & 0.695 & 0.288 & $0.581^{*}$ & 0.131 & 0.958 & 0.141 & $0.904^{*}$ & 0.180 \\
\hline Area of residence, ref.: urban & $1.417^{* * *}$ & 0.093 & $1.408^{* *}$ & 0.111 & $1.573^{*}$ & 0.057 & $2.804^{* *}$ & 0.571 \\
\hline \multicolumn{9}{|l|}{ Need factors } \\
\hline \multicolumn{9}{|c|}{ Self-reported health status (value on VAS), ref.: excellent } \\
\hline Good & 1.223 & 0.223 & $1.435^{* *}$ & 0.217 & 1.032 & 0.061 & 1.508 & 0.991 \\
\hline Fair & 0.931 & 0.147 & 1.207 & 0.413 & 1.370 & 0.099 & 1.349 & 0.409 \\
\hline Poor & $1.309^{* *}$ & 0.109 & $2.509^{* *}$ & 0.509 & 1.234 & 0.155 & 2.097 & 1.518 \\
\hline Depression, ref.: not depressed & $1.437^{* *}$ & 0.200 & 1.234 & 0.495 & $1.003^{* *}$ & 0.063 & $1.093^{*}$ & 0.209 \\
\hline Smoking, ref:: smoked & 1.237 & 0.313 & 1.496 & 0.190 & 0.926 & 0.095 & 0.682 & 0.209 \\
\hline Drinking, ref.: drank & $0.601^{*}$ & 0.134 & 0.957 & 0.310 & 1.008 & 0.058 & 1.588 & 0.970 \\
\hline \multicolumn{9}{|l|}{ Chronic disease, ref:: 0} \\
\hline One chronic disease & $1.985^{* * *}$ & 0.433 & $1.973^{* *}$ & 0.259 & $0.744^{* * *}$ & 0.038 & 1.210 & 0.506 \\
\hline Multiple chronic diseases & $3.063^{* * *}$ & 0.908 & $2.522^{*}$ & 0.648 & $0.253^{* *}$ & 0.021 & 1.606 & 0.974 \\
\hline \multicolumn{9}{|l|}{ Year, ref:. 2008} \\
\hline 2013 & $0.861^{* * *}$ & 1.032 & 0.909 & 0.280 & $0.773^{* *}$ & 0.148 & 1.107 & 0.579 \\
\hline 2018 & $0.603^{* * *}$ & 0.243 & $0.547^{* *}$ & 0.109 & $0.581^{*}$ & 0.230 & $0.487^{*}$ & 0.105 \\
\hline Year2013* Social health insurance & $0.609^{* *}$ & 0.083 & 1.064 & 0.896 & 0.896 & 0.287 & $0.541^{*}$ & 0.078 \\
\hline Year2018* Social health insurance & $0.235^{* *}$ & 0.131 & $0.432^{* *}$ & 0.090 & 0.609 & 0.172 & $0.309^{* *}$ & 0.091 \\
\hline
\end{tabular}

Note: *** indicates $p$ value $<0.001,{ }^{* *}$ indicates $p$ value $<0.01,{ }^{*}$ indicates $p$ value $<0.05, S D$ standard deviation, $O R$ odd ratio

services resulting from financial problems (one: $\mathrm{OR}=$ 1.997; multiple: $\mathrm{OR}=2.624)$. Respondents in 2018 and 2013 were significantly less likely to report inpatient underutilization resulting from financial issues in comparison with individuals in 2008 , and the odds ratio was estimated to be lower in 2018. Moreover, people having health insurance in 2018 also indicated a significantly lower likelihood of non-use of inpatient services 
Table 5 Logistic regression of unmet healthcare needs among people living in urban areas

\begin{tabular}{|c|c|c|c|c|c|c|c|c|}
\hline & \multicolumn{2}{|c|}{$\begin{array}{l}\begin{array}{l}\text { Non-use of } \\
\text { outpatient } \\
\text { services }\end{array} \\
\end{array}$} & \multicolumn{2}{|c|}{$\begin{array}{l}\text { Non-use of } \\
\text { inpatient } \\
\text { services }\end{array}$} & \multicolumn{2}{|c|}{$\begin{array}{l}\text { Non-use of } \\
\text { physical } \\
\text { examination }\end{array}$} & \multicolumn{2}{|c|}{$\begin{array}{l}\text { Early discharge } \\
\text { from hospital }\end{array}$} \\
\hline & OR & SD & OR & SD & OR & SD & OR & SD \\
\hline \multicolumn{9}{|l|}{ Predisposing factors } \\
\hline Sex, ref:: male & 1.148 & 0.427 & 0.829 & 0.391 & 0.892 & 0.532 & 0.804 & 0.290 \\
\hline \multicolumn{9}{|l|}{ Age (years), ref.: $\leq 30$} \\
\hline $30-45$ & 1.709 & 0.743 & 1.096 & 0.413 & 0.934 & 0.561 & 2.484 & 1.509 \\
\hline $45-60$ & $1.937^{* *}$ & 0.418 & 1.579 & 0.735 & $0.839^{* *}$ & 0.211 & 2.299 & 1.280 \\
\hline$>60$ & $1.897^{* * *}$ & 0.502 & $1.227^{* *}$ & 0.186 & $0.320^{* * *}$ & 0.094 & 1.927 & 1.142 \\
\hline Marital status, ref.: not married & $0.749^{*}$ & 0.158 & $1.177^{*}$ & 0.230 & $0.801^{* *}$ & 0.227 & 0.876 & 0.298 \\
\hline \multicolumn{9}{|l|}{ Education level, ref.: less than lower secondary } \\
\hline Upper secondary \& vocational training & 0.902 & 0.416 & $0.901^{* *}$ & 0.187 & $0.810^{* * *}$ & 0.235 & $0.892^{*}$ & 0.208 \\
\hline Tertiary & $0.528^{* *}$ & 0.201 & $0.473^{* * *}$ & 0.104 & $0.407^{* * *}$ & 0.103 & $0.533^{*}$ & 0.118 \\
\hline \multicolumn{9}{|l|}{ Employment status, ref.: employment } \\
\hline Unemployment & $1.311^{* *}$ & 0.198 & $1.307^{* * *}$ & 0.311 & $1.630^{*}$ & 0.413 & 1.191 & 0.413 \\
\hline Retired & 1.505 & 0.479 & 1.028 & 0.279 & $1.419^{* * *}$ & 0.211 & 1.485 & 0.290 \\
\hline Family size, ref:. $\leq 2$ & 0.884 & 0.517 & 0.955 & 0.618 & 0.997 & 0.359 & 0.908 & 0.305 \\
\hline \multicolumn{9}{|l|}{ Enabling factors } \\
\hline Social health insurance, ref.: have no social medical health insurance & $0.637^{* *}$ & 0.210 & $0.610^{* *}$ & 0.204 & $0.953^{*}$ & 0.249 & $0.793^{* *}$ & 0.238 \\
\hline \multicolumn{9}{|l|}{ Income level, ref.: $\leq ¥ 13,334$} \\
\hline$¥ 13,334-24,915$ & 0.811 & 0.167 & 0.807 & 0.492 & 0.992 & 0.475 & 1.138 & 0.523 \\
\hline$¥ 24,915-39,967$ & 0.774 & 0.225 & 0.906 & 0.298 & 0.758 & 0.343 & 0.872 & 0.503 \\
\hline$>¥ 39,967$ & $0.804^{* *}$ & 0.174 & $0.588^{* *}$ & 0.104 & $0.479^{* * *}$ & 0.213 & $0.849^{*}$ & 0.176 \\
\hline Financial subsidies: ref:: have financial subsidies & 1.100 & 0.590 & $0.905^{*}$ & 0.228 & 1.381 & 0.509 & $0.871^{*}$ & 0.203 \\
\hline \multicolumn{9}{|l|}{ Need factors } \\
\hline \multicolumn{9}{|l|}{ Self-reported health status (value on VAS), ref.: excellent } \\
\hline Good & 1.588 & 0.530 & 1.843 & 0.998 & 1.227 & 0.589 & 1.408 & 0.690 \\
\hline Fair & 0.990 & 0.491 & 1.266 & 0.680 & 1.183 & 0.391 & 1.249 & 0.754 \\
\hline Poor & $1.098^{* * *}$ & 0.199 & $1.320^{*}$ & 0.388 & 1.909 & 0.998 & 1.907 & 0.904 \\
\hline Depression, ref.: not depressed & $1.554^{* *}$ & 0.379 & $1.579^{* *}$ & 0.193 & $1.202^{*}$ & 0.236 & $1.190^{*}$ & 0.183 \\
\hline Smoking, ref:: smoked & 1.073 & 0.405 & 1.379 & 0.590 & 0.838 & 0.455 & 1.093 & 0.158 \\
\hline Drinking, ref.: drank & $0.805^{* *}$ & 0.217 & $0.821^{*}$ & 0.303 & 1.384 & 0.849 & 0.953 & 0.418 \\
\hline \multicolumn{9}{|l|}{ Chronic disease, ref:: 0} \\
\hline One chronic disease & $1.326^{* * *}$ & 0.126 & $2.075^{* *}$ & 0.310 & $0.522^{* * *}$ & 0.109 & 0.973 & 0.381 \\
\hline Multiple chronic disease & $1.182^{* *}$ & 0.321 & $1.912^{* * *}$ & 0.274 & $0.256^{* * *}$ & 0.071 & 1.278 & 0.671 \\
\hline \multicolumn{9}{|l|}{ Year, ref.:2008 } \\
\hline 2013 & 0.891 & 0.391 & 0.933 & 0.438 & $0.917^{* *}$ & 0.208 & 0.923 & 0.293 \\
\hline 2018 & $0.502^{*}$ & 0.179 & 0.827 & 0.311 & $0.718^{* *}$ & 0.124 & $0.809^{* *}$ & 0.243 \\
\hline Year2013*Social health insurance & 0.722 & 0.439 & 1.079 & 0.591 & 1.145 & 0.516 & 0.917 & 0.448 \\
\hline Year2018*Social health insurance & $0.689^{* *}$ & 0.173 & 0.805 & 0.388 & $0.947^{*}$ & 0.207 & 0.675 & 0.289 \\
\hline
\end{tabular}

Note: *** indicates $p$ value $<0.001,{ }^{* *}$ indicates $p$ value $<0.01,{ }^{*}$ indicates $p$ value $<0.05$, SD standard deviation, $O R$ odd ratio

$(\mathrm{OR}=0.309)$ due to "Financial difficulties". Those who were female $(\mathrm{OR}=1.185)$, aged over $60(\mathrm{OR}=2.171)$, or unmarried $(\mathrm{OR}=1.375)$ were more likely to report early discharge from hospital due to the cause "Think oneself recovered". Meanwhile, individuals having a tertiary education $(\mathrm{OR}=0.639)$, in the highest income group $(\mathrm{OR}=$ 
Table 6 Logistic regression of unmet healthcare needs among people living in rural areas

\begin{tabular}{|c|c|c|c|c|c|c|c|c|}
\hline & \multicolumn{2}{|c|}{$\begin{array}{l}\text { Non-use of } \\
\text { outpatient } \\
\text { services }\end{array}$} & \multicolumn{2}{|c|}{$\begin{array}{l}\text { Non-use of } \\
\text { inpatient } \\
\text { services }\end{array}$} & \multicolumn{2}{|c|}{$\begin{array}{l}\text { Non-use of } \\
\text { physical } \\
\text { examination }\end{array}$} & \multicolumn{2}{|c|}{$\begin{array}{l}\text { Early discharge } \\
\text { from hospital }\end{array}$} \\
\hline & OR & SD & OR & SD & OR & SD & OR & SD \\
\hline \multicolumn{9}{|l|}{ Predisposing factors } \\
\hline Sex, ref:: male & 1.447 & 0.293 & 1.191 & 0.610 & $0.822^{* *}$ & 0.119 & 1.384 & 0.475 \\
\hline \multicolumn{9}{|l|}{ Age (years), ref:: $\leq 30$} \\
\hline $30-45$ & $1.822^{*}$ & 0.410 & 1.906 & 1.238 & 0.815 & 0.260 & 1.191 & 0.549 \\
\hline $45-69$ & $2.022^{* * *}$ & 0.605 & $1.508^{*}$ & 0.709 & $0.944^{*}$ & 0.128 & $1.527^{* *}$ & 0.318 \\
\hline$>60$ & $2.833^{* *}$ & 0.874 & $2.193^{* *}$ & 0.944 & $0.410^{* *}$ & 0.091 & $2.299^{* *}$ & 0.904 \\
\hline Marital status, ref:: not married & 1.407 & 0.830 & 1.310 & 0.855 & 1.380 & 0.473 & 1.138 & 0.710 \\
\hline \multicolumn{9}{|l|}{ Education level, ref:: less than lower secondary } \\
\hline Upper secondary \& vocational training & 1.190 & 0.268 & 1.105 & 0.488 & $0.699^{* * *}$ & 0.102 & 1.135 & 0.487 \\
\hline Tertiary & 1.038 & 0.409 & $0.653^{* *}$ & 0.179 & $0.544^{* * *}$ & 0.099 & $0.909^{*}$ & 0.232 \\
\hline \multicolumn{9}{|l|}{ Employment status, ref:: employment } \\
\hline Unemployment & 0.984 & 0.191 & $1.470^{*}$ & 0.333 & $1.903^{*}$ & 0.336 & 1.705 & 0.933 \\
\hline Retired & 1.122 & 0.287 & $1.277^{*}$ & 0.184 & $1.190^{* *}$ & 0.181 & 1.134 & 0.574 \\
\hline Family size, ref.: $\leq 2$ & $0.810^{*}$ & 0.180 & $0.739^{* * *}$ & 0.210 & 1.163 & 0.719 & 1.209 & 0.484 \\
\hline \multicolumn{9}{|l|}{ Enabling factors } \\
\hline Social health insurance, ref.: have no social medical health insurance & $0.770^{* *}$ & 0.218 & $0.291^{* * *}$ & 0.098 & 1.372 & 0.388 & $0.628^{* *}$ & 0.134 \\
\hline \multicolumn{9}{|l|}{ Income level, ref.: $\leq ¥ 13,334$} \\
\hline$¥ 13,334-24,915$ & 1.237 & 0.575 & $0.803^{*}$ & 0.193 & 0.788 & 0.238 & $0.871^{* *}$ & 0.214 \\
\hline$¥ 24,915-39,967$ & $0.717^{*}$ & 0.129 & 1.024 & 0.436 & $0.610^{* *}$ & 0.131 & $0.910^{*}$ & 0.165 \\
\hline$>¥ 39,967$ & $0.579^{* *}$ & 0.100 & $0.337^{* *}$ & 0.079 & $0.427^{* *}$ & 0.091 & $0.762^{* *}$ & 0.104 \\
\hline Financial subsidies: ref:: have financial subsidies & 0.474 & 0.187 & $0.657^{* *}$ & 0.184 & 0.983 & 0.318 & 0.904 & 0.354 \\
\hline \multicolumn{9}{|l|}{ Need factors } \\
\hline \multicolumn{9}{|l|}{ Self-reported health status (value on VAS), ref:: excellent } \\
\hline Good & 1.008 & 0.198 & 1.390 & 0.550 & 0.974 & 0.449 & $0.790^{*}$ & 0.111 \\
\hline Fair & $1.478^{*}$ & 0.311 & $1.905^{* *}$ & 0.338 & 1.135 & 0.681 & 1.353 & 0.381 \\
\hline Poor & $1.809^{*}$ & 0.284 & $2.497^{* * *}$ & 0.682 & 1.036 & 0.382 & 0.899 & 0.401 \\
\hline Depression, ref:: not depressed & 1.198 & 0.410 & 1.409 & 0.549 & $1.210^{* *}$ & 0.229 & $1.137^{*}$ & 0.204 \\
\hline Smoking, ref.: smoked & 1.471 & 0.625 & 1.191 & 0.781 & $0.997^{* * *}$ & 0.148 & 1.241 & 0.458 \\
\hline Drinking, ref.: drank & 1.191 & 0.406 & 0.903 & 0.359 & 0.974 & 0.402 & 0.977 & 0.319 \\
\hline \multicolumn{9}{|l|}{ Chronic disease, ref::0 } \\
\hline One chronic disease & $2.871^{* *}$ & 0.792 & $3.040^{*}$ & 0.939 & $0.609^{* *}$ & 0.103 & 1.228 & 0.514 \\
\hline Multiple chronic disease & $4.190^{* * *}$ & 0.690 & $6.093^{* * *}$ & 1.109 & $0.426^{* * *}$ & 0.074 & $1.033^{*}$ & 0.201 \\
\hline \multicolumn{9}{|l|}{ Year, ref.: 2008} \\
\hline 2013 & $0.917^{* *}$ & 0.209 & 1.099 & 0.824 & 0.737 & 0.198 & 1.036 & 0.578 \\
\hline 2018 & $0.362^{* *}$ & 0.087 & $0.634^{* *}$ & 0.162 & $0.608^{* * *}$ & 0.130 & $0.638^{* *}$ & 0.201 \\
\hline Year2013*Social health insurance & $0.847^{*}$ & 0.219 & $0.904^{* *}$ & 0.289 & 0.610 & 0.248 & 0.931 & 0.220 \\
\hline Year2018*Social health insurance & $0.493^{* *}$ & 0.170 & $0.312^{* *}$ & 0.108 & 0.484 & 0.150 & $0.271^{* *}$ & 0.083 \\
\hline
\end{tabular}

Note: *** indicates $p$ value $<0.001,{ }^{* *}$ indicates $p$ value $<0.01,{ }^{*}$ indicates $p$ value $<0.05, S D$ standard deviation, OR odd ratio

0.654), or having chronic disease demonstrated a significantly lower probability of early discharge from hospital resulting from thinking themselves recovered.
Discussion

Reducing unmet healthcare needs is very important for alleviating inequality in health services and achieving 
Table 7 Logistic regression of unmet healthcare needs caused by main reasons

\begin{tabular}{|c|c|c|c|c|c|c|}
\hline & \multicolumn{2}{|c|}{$\begin{array}{l}\text { Non-use of outpatient } \\
\text { services }\end{array}$} & \multicolumn{2}{|c|}{$\begin{array}{l}\text { Non-use of inpatient } \\
\text { services }\end{array}$} & \multicolumn{2}{|c|}{$\begin{array}{l}\text { Early discharge from } \\
\text { hospital }\end{array}$} \\
\hline & OR & SD & OR & SD & OR & SD \\
\hline \multicolumn{7}{|l|}{ Predisposing factors } \\
\hline Sex, ref.: male & $1.576^{*}$ & 0.314 & 0.736 & 0.304 & $1.185^{* *}$ & 0.190 \\
\hline \multicolumn{7}{|l|}{ Age (years), ref.: $\leq 30$} \\
\hline $30-45$ & 1.415 & 0.782 & 1.578 & 0.908 & 1.406 & 0.903 \\
\hline $45-60$ & $1.392^{* *}$ & 0.248 & 1.389 & 0.601 & $1.876^{* *}$ & 0.628 \\
\hline$>60$ & $1.838^{* *}$ & 0.178 & $1.739 * *$ & 0.505 & $2.171^{* *}$ & 0.918 \\
\hline Marital status, ref:: not married & 0.949 & 0.370 & 1.313 & 0.790 & $1.375^{*}$ & 0.291 \\
\hline \multicolumn{7}{|l|}{ Education level, ref:. less than lower secondary } \\
\hline Upper secondary \& vocational training & $0.829^{*}$ & 0.247 & 0.709 & 0.353 & 0.945 & 0.400 \\
\hline Tertiary & $0.597^{* *}$ & 0.186 & $0.874^{* *}$ & 0.227 & $0.639^{* *}$ & 0.194 \\
\hline \multicolumn{7}{|l|}{ Employment status, ref:: employment } \\
\hline Unemployment & 0.997 & 0.558 & $1.297^{* *}$ & 0.274 & 0.948 & 0.470 \\
\hline Retired & $0.495^{* * *}$ & 0.097 & 1.507 & 0.622 & 1.193 & 0.593 \\
\hline Family size, ref.: $\leq 2$ & 1.190 & 0.546 & $0.903^{*}$ & 0.114 & 1.354 & 0.742 \\
\hline \multicolumn{7}{|l|}{ Enabling factors } \\
\hline Social health insurance, ref.: have no insurance & 1.275 & 0.336 & $0.312^{* * *}$ & 0.083 & 0.875 & 0.501 \\
\hline \multicolumn{7}{|l|}{ Income level, ref.: $\leq ¥ 13,334$} \\
\hline$¥ 13,334-24,915$ & 0.974 & 0.483 & $0.629^{* *}$ & 0.148 & 1.094 & 0.590 \\
\hline$¥ 24,915-39,967$ & 0.850 & 0.324 & $0.310^{* * *}$ & 0.077 & 0.905 & 0.532 \\
\hline$>¥ 39,967$ & 0.645 & 0.290 & $0.202^{* * *}$ & 0.082 & $0.654^{*}$ & 0.212 \\
\hline Financial subsidies: ref:. have financial subsidies & 1.290 & 0.596 & $0.387^{* * *}$ & 0.115 & 1.099 & 0.601 \\
\hline Area of residence, ref.: urban & 0.840 & 0.250 & 1.179 & 0.596 & 1.178 & 0.578 \\
\hline \multicolumn{7}{|l|}{ Need factors } \\
\hline \multicolumn{7}{|c|}{ Self-reported health status (value on VAS), ref.: excellent } \\
\hline Good & 1.180 & 0.623 & 1.820 & 0.793 & 0.879 & 0.283 \\
\hline Fair & 0.908 & 0.421 & 1.576 & 0.669 & $0.913^{*}$ & 0.301 \\
\hline Poor & 0.718 & 0.207 & 1.845 & 0.858 & 0.698 & 0.411 \\
\hline Depression, ref.: not depressed & $0.747^{* *}$ & 0.190 & 1.094 & 0.480 & $0.855^{* *}$ & 0.146 \\
\hline Smoking, ref.: smoked & 1.009 & 0.393 & 1.003 & 0.502 & 1.084 & 0.394 \\
\hline Drinking, ref.: drank & 0.890 & 0.155 & 0.822 & 0.348 & 0.747 & 0.401 \\
\hline \multicolumn{7}{|l|}{ Chronic disease, ref::0 } \\
\hline One chronic disease & $0.735^{* * *}$ & 0.110 & $1.997^{* *}$ & 0.839 & $0.693^{*}$ & 0.171 \\
\hline Multiple chronic disease & $0.379^{* * *}$ & 0.130 & $2.624^{* *}$ & 1.095 & $0.402^{* *}$ & 0.103 \\
\hline \multicolumn{7}{|l|}{ Year, ref.:2008 } \\
\hline 2013 & 1.090 & 0.388 & $0.897^{*}$ & 0.248 & 1.403 & 0.834 \\
\hline 2018 & $0.954^{*}$ & 0.173 & $0625^{* *}$ & 0.173 & 0.811 & 0.338 \\
\hline Year2013*Social health insurance & 1.032 & 0.491 & 0.901 & 0.418 & 1.193 & 0.579 \\
\hline Year2018*Social health insurance & 0.832 & 0.290 & $0.309^{* *}$ & 0.104 & 0.975 & 0.628 \\
\hline
\end{tabular}

Note: ${ }^{* *}$ indicates $p$ value $<0.001,{ }^{* *}$ indicates $p$ value $<0.01,{ }^{*}$ indicates $p$ value $<0.05, S D$ standard deviation, OR odd ratio

universal health coverage [22]. Although many studies have explored healthcare utilization and underutilization, little research has examined the association between universal health insurance coverage and unmet healthcare needs. In this study, we analyzed the prevalence of, main reasons for, and trends in unmet healthcare needs over the period of the introduction of universal health insurance coverage in China and make comparisons between 
urban and rural areas. Additionally, we estimated the effects of universal health insurance coverage and other socioeconomic factors on unmet healthcare needs.

\section{Prevalence, main reasons and trends of unmet healthcare needs}

On the whole, the degrees of reported non-use of outpatient services, inpatient services, physical examinations, and early discharge from hospital in Jiangsu Province were significantly different. The prevalence of non-use of physical examinations was much higher than other kinds of healthcare services, which may be due to physical examinations not being included in China's health insurance system and people lacking awareness of preventive healthcare. Hence, policy efforts should focus on further expanding the service package of health insurance and adopting strategies to improve the effective utilization of preventive healthcare [12].

The prevalence of unmet healthcare needs in rural areas was found to be generally higher than that in urban areas, which is in line with previous surveys [22, 30, 31, 33]. The main reason for outpatient underutilization overall and in urban areas was "Illness is not serious", while in rural areas it was "No effective treatment", a discrepancy that may be caused by highquality medical resources tending to be allocated to urban areas in China [41]. Therefore, narrowing the gap in allocation of health resources between urban and rural areas should be an effective way to alleviate unmet outpatient needs. The prevalence of non-use of inpatient services and physical examinations was higher among people in rural areas than in urban areas, and financial problems were always the main obstacle to rural residents using inpatient services. This finding reflects the huge economic discrepancy between urban and rural areas in China.

Aside from the non-use of inpatient services, the trends in unmet healthcare needs in urban and rural areas were similar, showing a decline from 2008 to 2018, across the period of implementation of universal health insurance coverage in China. The rate of non-use of inpatient services remained relatively lower and was flat from 2008 to 2018, revealing that, in addition to economic factors, the severity of a person's disease may mainly determine their choice of inpatient services. Therefore, the rate of non-use of inpatient services remained low and stable. It should be noted that the outpatient underutilization rate showed a dramatic rise from 2008 to 2013, followed by a significant decline from 2013 to 2018. In the early stage of the New Medical Reform Plan in 2009, China's health insurance coverage rate increased rapidly, but the reimbursement ratio remained low, meaning unmet outpatient service needs continued to increase. The rate of unmet outpatient service needs may have started to decline after 2013 as a result of improvement in the reimbursement level of the health insurance system.

\section{Association between insurance and its universal coverage and unmet healthcare needs}

Health insurance had a significant impact on the reduction of health service underutilization, except for in the case of physical examinations services. With regard to the annual effect, the probability of non-use of outpatient services and physical examinations significantly declined both in 2013 and 2018, and the likelihood of non-use of inpatient services and early discharge from hospital also significantly reduced in 2018. This finding indicates that unmet healthcare needs were alleviated with the development of the economy and deepening medical reform in China. People having health insurance in 2013 and 2018 demonstrated a significantly lower likelihood of non-use of outpatient services and early discharge from hospital, and the odds ratios decreased over time. This finding reflects a continuously positive role of universal health insurance coverage on reducing unmet healthcare needs. However, the effect on non-use of inpatient services was relatively weak.

In addition, the effect of health insurance and its universal coverage on reducing unmet healthcare needs was estimated to be greater in rural than in urban areas. Therefore, universal health insurance coverage played a greater role in promoting effective health utilization in rural areas [42]. Since the prevalence of unmet healthcare needs in rural areas was higher than that in urban areas, policies should focus on further improving the health insurance system for rural residents, for example by achieving full coverage, gradually increasing the reimbursement level and expanding the service package of health insurance, to alleviate the inequality in healthcare utilization between urban and rural areas.

Universal health insurance coverage only significantly affected non-use of inpatient services caused by financial difficulties. This is mainly due to the fact that health insurance is an important economic guarantee for inpatients. The effect of health insurance on reducing the non-use of inpatient services was significant in 2018, indicating that the reform and adjustment of health insurance in recent years, such as the policy of critical illnesses payment and extending the national medicine catalog of medical insurance, may ease the economic burden on patients and promote the utilization of hospitalization.

\section{Other associated factors of unmet healthcare needs}

Other demographic or socioeconomic factors associated with unmet healthcare needs included age, educational 
level, income level, area of residence, self-reported health status, depression, and chronic diseases. Specifically, older people were significantly less likely to report underutilization of physical examinations [43, 44]. The prevalence of chronic diseases and resultant disabilities was higher among the elderly, and this may lead to a greater need for physical examinations [45]. However, the association between the other three kinds of unmet healthcare needs and age was found to be the opposite, which is in contrast to other reports [12, 14, 46, 47]. Higher education was associated with lower prevalence of non-use of healthcare services, which is in line with work by $\mathrm{Li}$ et al. [48]. Therefore, the government could promote residents' health awareness by improving education, and this may boost the effective utilization of healthcare. The unemployed or retired were more likely to face barriers in obtaining needed health services [12, 13, 19, 48]. Compared with urban residents, rural residents who were unemployed, retired, or who had lower income demonstrated a higher likelihood of having unmet healthcare needs, especially inpatient services. Therefore, strategies such as increasing financial support, widening employment channels in rural areas, and adjusting the urban and rural income distribution system should be implemented to promote healthcare utilization among these people.

Consistent with existing reports [45, 46, 49-52], the overall likelihood of non-use of outpatient and inpatient services was significantly higher among those with lower self-reported health status, who were depressed, or who had chronic diseases. This may be explained by the fact that people who are depressed or have chronic diseases are generally accompanied by long-term or lifelong treatment and medication, which will certainly result in them having more unmet healthcare needs than healthy individuals, especially if there is a lack of patient compliance [12]. However, having chronic diseases was significantly associated with lower underutilization of physical examinations, indicating that chronic patients may have a stronger awareness of disease prevention $[12,15]$.

Some limitations of our study must be acknowledged. First, unmet healthcare needs in this paper only refer to people who perceived a need for healthcare but did not seek treatment; those who did not perceive a need for healthcare were not included. Therefore, the prevalence of unmet healthcare needs might have been underestimated to some extent. Also, we did not consider the moral hazard which might overestimate the likelihood of unmet healthcare needs to some extent. In addition, partial voluntariness of URMI might lead to adverse selection and affect the results to a certain extent. Finally, the data in our study was from the Jiangsu Province data in the NHSS, which may not be nationally representative.

\section{Conclusions}

Our findings suggest that health insurance significantly reduced unmet healthcare needs in Jiangsu Province. People having health insurance in 2013 and 2018 demonstrated a significantly lower likelihood of non-use of outpatient services and early discharge from hospital, and the odds ratios decreased over time. In addition, the prevalence of unmet healthcare needs in rural areas was found to be higher than that in urban areas, meanwhile universal health insurance coverage played a greater role in reducing unmet healthcare needs in rural areas. Therefore, achieving full coverage and gradually increasing the reimbursement level and expanding the service package of health insurance should be an effective way to promote effective health utilization in rural areas and alleviate the inequality in healthcare utilization between urban and rural areas. Other socioeconomic factors, such as age, marital status, educational level, employment status, income level, and health status, were found to significantly affect unmet healthcare needs. Therefore, policy efforts need to address these factors to promote effective healthcare utilization by residents.

\section{Acknowledgements}

We would like to acknowledge Chinese National Health Commission and local Health Commission of Jiangsu province for their cooperation. We would also like to thank all study participants for their time to be interviewed.

\section{Authors' contributions}

SZ led the analysis of the data and wrote the first draft of the manuscript; ZW contributed to the study design, interpretation of the data and helped in the writing of the final draft of the manuscript; TH and AL helped in data analysis and contributed in writing. All authors read and approved the final manuscript

\section{Funding}

This study is founded by the National Office for Philosophy and Social Sciences of China (no.18BGL243). The funding bodies were not involved in the design of the study, or data collection, analysis, and interpretation or in writing the manuscript.

\section{Availability of data and materials}

The datasets used in the current study are not publicly available due to the confidential policy but are available from the corresponding author on reasonable request.

\section{Ethics approval and consent to participate}

This study was approved by the Academic Research Ethics Committee of Nanjing Medical University. All procedures were in accordance with the ethical standards of the Helsinki Declaration. Participants provided informed consent prior to data collection.

Consent for publication

Not applicable.

\section{Competing interests}

The authors declare that they have no competing interests.

\section{Author details}

${ }^{1}$ School of Health Policy \& Management, Nanjing Medical University, 101Longmian Avenue, Jiangning District, Nanjing 211166, P.R. China.

${ }^{2}$ Creative Health Policy Research Group, Nanjing Medical University, Nanjing 211166, China. ${ }^{3}$ Center for Global Health, Nanjing Medical University, Nanjing 211166, China. 
Received: 23 September 2020 Accepted: 12 January 2021

\section{Published online: 21 January 2021}

\section{References}

1. Meng Q. Universal health coverage: from concept to action. Chin J Health Policy. 2014;7(02):1-4.

2. WHO. Universal health coverage. Chin Gen Prac. 2018;21(04):389.

3. Shi A. Evaluation of the effect of basic medical insurance policy. Foreign Economic and Trade University; 2018.

4. Zhou Q, Liu GG, Krumholz S. Is Chinese National Health Insurance effective in the face of severe illness? a perspective from health service utilization and economic burden. Soc Indic Res. 2017;132(3):1-23.

5. Wang E. Who benefits from the new rural cooperative medical system *__ also on the fairness of health and medical service utilization. Rural Econ. 2012;02:84-8.

6. Chen Q, Fu H, Li L. Overall effect of medical insurance: evidence from universal medical insurance in China. Stud Labor Econ. 2016:4(06):3-21.

7. Jiang C, Ma J. Analyzing the role of overall basic medical insurance in the 740 process of universal health coverage. Chin Health Serv Manage. 2015; 32(02):108-110+141.

8. UNICEF. Health insurance coverage, 1998, 2003, 2008 and 2013. https:// www.unicef.cn/en/figure-325-health-insurance-coverage-1998-2003-2008and-2013. Accessed 28 Aug 2020.

9. Sibley LM, Glazier RH. Reasons for self-reported unmet healthcare needs in Canada: a population-based provincial comparison. Health Policy. 2009;5(1):87-101.

10. CPC Central Committee and State Council. Decision of the CPC Central Committee and the State Council on Further Strengthening Rural Health Work. Chin Health Qual Manage. 2003;01:6-9.

11. World Health Organization. Health systems financing: the path to universal coverage. World health report 2010. Geneva: World Health Organization; 2010.

12. Jiang C, Ma J. Analyzing the role of overall basic medical insurance in the process of universal health coverage. Chin Health Serv Manag. 2015;2:108-10+14.

13. Carr W, Wolfe S. Unmet needs as Sociomedical indicators. Int J Health Serv. 1976;6(3):417-30.

14. Röttger J, Blümel M, Köppen J, et al. Forgone care among chronically ill patients in Germany - results from a cross-sectional survey with 15,565 individuals. Health Policy. 2016;120(2):170-8.

15. Lucevic A, Péntek M, Kringos $D$, et al. Unmet medical needs in ambulatory care in Hungary: forgone visits and medications from a representative population survey. Eur J Health Econ. 2019;20:71-8.

16. Jenkins SP. Le GrandJulian, Equity and Choice: an Essay in Economics and Applied Philosophy, Harper Collins, London, 1991. 190 pp. 35.00. paper 10. 95. J Soc Policy. 1993;22(02):280.

17. Allin S, Grignon M, Grand JL. Subjective unmet need and utilization of health care services in Canada: what are the equity implications? Soc Sci Med. 2010;70(3):465-72.

18. Thiede M, Akweongo P, Mclntyre D. Exploring the dimensions of access. The economics of health equity: Cambridge University Press; 2007. p. 10323. https://doi.org/10.1017/CBO9780511544460.007

19. Gong $\mathrm{CH}$, Kendig $\mathrm{H}$, He X. Factors predicting health services use among older people in China: an analysis of the China health and retirement longitudinal study 2013. BMC Health Serv Res. 2016;16(1):63.

20. Zhou C, Ji C, Chu J, et al. Non-use of healthcare service among empty-nest elderly in Shandong, China: a cross-sectional study. BMC Health Serv Res. 2015;15:294.

21. Bryant T, Leaver C, Dunn J. Unmet healthcare need, gender, and health inequalities in Canada. Health Policy. 2009;91:24-32.

22. Ronksley PE, Sanmartin C, Quan H, et al. Association between chronic conditions and perceived unmet healthcare needs. Open Med. 2012;6:e48.

23. Tchicaya A, Lorentz N. Socioeconomic inequalities in the non-use of dental care in Europe. Int J Equity Health. 2014;13(1):7.

24. Andersen R, Newman JF. Societal and individual determinants of medical care utilization in the United States. Milbank Mem Fund Q Health Soc. 1973; 51(1):95-124.

25. Figueras J, McKee M, Lessof S, et al. Health systems, health and wealth: assessing the case for investing in health systems. 2008.

26. OECD. Health at a Glance 2015: OECD Indicators. Paris: OECD Publishing; 2015. https://doi.org/10.1787/health_glance-2015-en

27. Li X, Chen M, Wang Z, et al. Forgone care among middle aged and elderly with chronic diseases in China: evidence from the China health and retirement longitudinal study baseline survey. BMJ Open. 2018:8(3):e019901.
28. Kondo A, Shigeoka H. Effects of universal health insurance on healthcare utilization, and supply-side responses: evidence from Japan. J Public Econ. 2013;99:1-23.

29. Chen J, Hou F. Unmet needs for healthcare. Health Rep. 2002;13(2):23-32.

30. Luo J, Zhang $X$, Jin $C$, et al. Inequality of access to healthcare among the urban elderly in northwestern China. Health Policy. 2009;93(2-3):111-7.

31. $Y u Q, H u$ W, Fang $L$, et al. Comparative study on the utilization of outpatient health services for urban and rural residents in Guangdong Province. Int Med Health Guid News. 2019;25(7):1035-8.

32. Yang J, Zhang G, Qian $Y$, et al. Analysis on health demands and use of the 803 outpatient health services in rural and urban areas in Ningxia. Ningxia Med J. 2016;38(01):39-41.

33. Wang N, Shi S, Fan J, et al. Unused inpatient service and its influencing factors of residents in Henan Province. J Zhengzhou Univ (Medical Sci). 2016;51(3):368-72

34. Ying G, Gan H, Li X, et al. The unused inpatient service of urban and rural residents and its influencing factors in Sichuan province. Mod Prev Med. 2011;38(6):1045-7.

35. Junfang W, Biao Z, Weijun Z, et al. Perceived unmet need for hospitalization service among elderly Chinese people in Zhejiang Province. J Public Health. 2009:4:530-40.

36. Albanese $\mathrm{E}$, Liu Z, Acosta D, et al. Equity in the delivery of community healthcare to older people: findings from 10/66 dementia research group cross-sectional surveys in Latin America, China, India and Nigeria. BMC Health Serv Res. 2011;11:153.

37. Wang L, Kong L, Wu F, et al. Preventing chronic diseases in China. Lancet. 2005;366(9499):1821-4.

38. Allin S, Masseria C. Research note: unmet need as an indicator of access to healthcare in Europe. London: European Commission Directorate-General Employment, Social Affairs and Equal Opportunities; 2009.

39. Levesque J-F, Pineault $R$, Hamel M, et al. Emerging organisational models of primary healthcare and unmet needs for care: insights from a populationbased survey in Quebec province. BMC Fam Pract. 2012;13(1):66.

40. de Boer AGEM, Wijker W, de Haes HCJM. Predictors of healthcare utilization in the chronically ill: a review of the literature. Health Policy. 1997;42(2):101-15.

41. Fernández-Olano C, López-Torres Hidalgo JD, Cerdá-Díaz R, et al. Factors associated with healthcare utilization by the elderly in a public healthcare system. Health Policy. 2006;75(2):131-9.

42. Yin Z, Wang N, Wang B. Research on the evaluation and effectiveness of the major medical Insurance for Urban and Rural Residents. J Suihua Univ. 2017; 14(3):186-92.

43. Wong R, Díaz JJ. Health care utilization among older Mexicans: health and socioeconomic inequalities. Salud Pública Mex. 2007;49(S4):S505.

44. Blay SL, Fillenbaum GG, Andreoli SB, Gastal FL. Equity of access to outpatient care and hospitalization among older community residents in Brazil. Med Care. 2008:46(9):930-7.

45. Wang Z, Li X, Chen M, et al. Social health insurance, healthcare utilization, and costs in middle-aged and elderly community-dwelling adults in China. Int J Equity Health. 2018;17(1):17.

46. Peytremann-Bridevaux I, Chevrou-Severac $\mathrm{H}$. Economic grand rounds: financial burden of medical care and risk of forgoing care among Europeans with depressive symptoms. Psychiatr Serv. 2008;59:840-2.

47. Goddard M, Smith P. Equity of access to healthcare services: theory and evidence from the UK. Soc Sci Med. 2001;53(9):1149-62.

48. Li A, Chen M, Wang Z. Status and equity analysis of nonuse of health services in middle-aged and elderly chronic disease people. Chin Gen Med. 2019:022(022):2728-34

49. Liu H, Zhao Z. Does health insurance matter? Evidence from China's urban resident basic medical insurance. J Comp Econ. 2014;42(4):1007-20.

50. Huang F, Li G. The impacts of China's urban employee basic medical insurance on healthcare expenditures and health outcomes. Health Econ. 2015;26(2):149-63.

51. Chen H, Deng P. Health effect evaluation of the urban employee basic medical insurance. Soc Secur Stud. 2016:30(4):110-8.

52. Xu J, Zheng J, Li J, et al. Needs, utilization and equity of health services among urban and rural residents in the process toward achieving universal health coverage. Chin Gen Pract. 2018;021(034):4163-8.

\section{Publisher's Note}

Springer Nature remains neutral with regard to jurisdictional claims in published maps and institutional affiliations. 